\title{
Is the IDH Mutation a Good Target for Chondrosarcoma Treatment?
}

\author{
Elena Cojocaru ${ }^{1} \cdot$ Christopher Wilding $^{2} \cdot$ Bodil Engelman $^{1} \cdot$ Paul Huang $^{2} \cdot$ Robin L. Jones $^{1,2}$
}

Published online: 11 January 2020

(C) The Author(s) 2020

\begin{abstract}
Chondrosarcomas are rare cancers of bone that arise from the malignant transformation of cells of chondrocytic lineage. They are known to be resistant to systemic cytotoxic chemotherapy and radiotherapy. The mainstay of management of localised disease is en bloc surgical resection with curative intent. Metastatic chondrosarcoma has a dismal prognosis, and to date, there are no proven effective systemic therapies in the advanced setting. Genomic studies have demonstrated that 50 to $80 \%$ of chondrosarcomas harbour a mutation in either the $I D H 1$ or $I D H 2$ gene. IDH inhibitors are currently under investigation in clinical trials, after showing promising results in phase 1 studies in $I D H$ mutated cancers. In chondrosarcoma, $I D H$ mutations represent an attractive target, however, early results with IDH inhibitors in $I D H$ mutated chondrosarcoma are modest and the final results of ongoing trials are eagerly awaited.
\end{abstract}

Keywords Chondrosarcoma $\cdot I D H \cdot$ Advanced disease $\cdot$ Systemic therapy $\cdot$ IDH inhibitor

\section{Role of IDH Family of Proteins in Homeostasis and Mutations in Cancer}

Isocitrate dehydrogenase (IDH) is a family of enzymes which play a crucial role in the Krebs cycle. IDH catalyses the oxidative decarboxylation of isocitrate, producing alpha-ketoglutarate $(\alpha-$ $\mathrm{KG}$ ); nicotinamide adenine dinucleotide phosphate (NADH), the reduced form NADPH; and carbon dioxide [1, 2]. Alpha-KG epigenetically controls gene expression through $\alpha$-KGdependant dioxygenase, by inhibition of 2-oxoglutarate(OG)-dependant chromatin-modifying enzymes, including histone demethylases and methylcytosine dioxygenases of the TET family that regulates the cellular epigenetic status [3]. In humans, IDH exists as 3 isoforms. IDH1 and IDH2 are homodimers that utilise nicotinamide adenine dinucleotide phosphate $\left(\mathrm{NADP}^{+}\right)$as a cofactor. IDH3 is a heterotetrameric isozyme and employs

Paul Huang and Robin Jones contributed equally to this work.

This article is part of the Topical Collection on Molecular Pathology of Skeletal Tumors

Robin L. Jones

robin.jones4@nhs.net

1 Sarcoma Unit, The Royal Marsden NHS Foundation Trust, Fulham Road, London SW3 6JJ, UK

2 Institute of Cancer Research, Chester Beatty Laboratories, 237 Fulham Rd, Chelsea, London SW3 6JB, UK adenine dinucleotide $\left(\mathrm{NAD}^{+}\right)$as a cofactor, resulting in the final product of NADH [2]. The normal functioning of the Krebs cycle, also known as tricarboxylic acid cycle (TCA), is vital for cellular metabolism, redox balance, epigenetic regulations and DNA repair $[4,5]$.

Mutations in the $I D H 1$ and $I D H 2$ genes are known to be tumorigenic, however, mutations in the $I D H 3$ gene have not been correlated with cancers in humans [6-8]. The altered amino acids mostly affected are the R132 in IDH1 and the $\mathrm{R} 172$ and R140 in the $I D H 2$ gene. The resultant mutated proteins have neomorphic activity, converting $\alpha-\mathrm{KG}$ to D-2hydroxyglutarate (D-2-HG), an oncometabolite, using NADPH as a cofactor [9]. In the normal metabolic state, cellular 2-HG accumulation is limited by endogenous 2-HG dehydrogenase enzymes, which catalyse the conversion of 2-HG to $\alpha-\mathrm{KG}$. In mutated cells, however, the $2-\mathrm{HG}$ can be as much as 100-fold increased and the accumulation of 2-HG affects $\mathrm{CpG}$ island and histone methylation, leading to genome-wide histone and DNA methylation alterations [10].

\section{Cancers Associated with IDH Mutations}

$I D H 1$ and $I D H 2$ mutations have been identified in solid tumours including glioma, chondrosarcoma, cholangiocarcinoma and haematological malignancies such as acute myeloid leukaemia (AML). 


\section{Glioblastoma}

Recurrent $I D H 1$ and $I D H 2$ mutations have been identified in more than $80 \%$ of low-grade gliomas and secondary glioblastomas (GBM), whilst less than $10 \%$ of primary GBM harbour a mutation in the $I D H$ genes [11, 12]. Of note, the presence of an $I D H$ mutation is associated with a better prognosis in $I D H$ mutant tumours [13]. Due to the high incidence of $I D H$ aberrations in secondary GBM, mutational status could act as a biomarker to distinguish between primary and secondary GBM.

\section{Acute Myeloid Leukaemia}

Whole-genome and exome sequencing studies have revealed recurrent $I D H 1$ and 2 mutations in 15-20\% of newly diagnosed acute myeloid leukaemia (AML). Production of high levels of 2-HG in $I D H 1$ and $I D H 2$ mutated cases leads to DNA hypermethylation via the TET family of proteins. As a result, expression of the Hox family of homeodomain transcription factors that controls morphogenesis and cellular differentiation is increased in association with the presence of IDH mutations and promotes DNA hypermethylation, aberrant cell proliferation and leukaemic cell differentiation [14-16]. In a murine model, the combination of IDH1 mutation and the expression of HoxA9 promoted a myeloproliferative phenotype [12]. In contrast to GBM, the presence of an $I D H$ mutation in AML has been associated with a poorer prognosis $[17,18]$.

\section{Cholangiocarcinoma}

Mutations in the $I D H 1$ and $I D H 2$ genes are found in 15-20\% of intrahepatic cholangiocarcinomas [19, 20]. Saha and colleagues demonstrated the mechanism of tumorigenesis in transgenic mice, with $I D H$ mutations resulting in the production of 2-HG and suppression of hepatocyte nuclear factor 4 alpha (HNF-4 $\alpha$ ), an important regulator of hepatocyte differentiation and dormancy status. Hence, mutant $I D H$ will block liver progenitor cells from differentiating into hepatocytes and will promote abnormal cell proliferation and tumorigenesis [21]. Moreover, co-existence of both KRAS and IDH1 mutations in the same murine tumour promoted aberrant cell proliferation and metastasis of intrahepatic cholangiocarcinoma cells [21].

\section{Chondrosarcoma}

$I D H 1$ or $I D H 2$ mutations have been reported in $50-80 \%$ of chondrosarcomas $[22,23]$. This review will focus on $I D H$ mutations in chondrosarcoma and its precursors, as well as the latest research in targeting the IDH mutant protein with therapeutic agents.

\section{Current Therapeutic Approaches in Chondrosarcoma}

Chondrosarcoma is a rare malignancy, being the $3 \mathrm{rd}$ most common bone cancer after myeloma and osteosarcoma. Chondrosarcoma is characterised by a dense extracellular matrix, poor vascularisation and a low percentage of dividing cells. Due to these properties, the metastatic potential of chondrosarcoma is less than that of other cancers [24]. Complete en bloc surgical resection is the gold standard treatment and should be offered whenever feasible. Generally, chondrosarcoma is chemo- and radiation-resistant, and the treatment of advanced disease poses a huge clinical challenge $[25,26]$.

Conventional chondrosarcomas account for almost $90 \%$ of all chondrosarcomas. The majority (85\%) of conventional chondrosarcoma are centrally occurring, arising in the medullary cavity of bones, whilst the remaining $15 \%$ are peripheral and grow outwards from the surface of the bone.

Other rare subtypes of chondrosarcoma have been described, accounting for 10-15\% of chondrosarcomas [27]. The most common subtypes are dedifferentiated (a highgrade non-cartilaginous sarcoma), clear cell, mesenchymal (formed of a chondro-osseous and a blue round cell component), juxtacortical and secondary chondrosarcoma [28]. Myxoid chondrosarcoma of the bone or skeletal myxoid chondrosarcoma (SMC), a distinct entity to extra-skeletal myxoid chondrosarcoma (EMC), is a newly described subtype and is likely a variant of conventional chondrosarcoma [27]. EMC has a higher potential for metastasis than other chondrosarcoma subtypes [29].

As well as demonstrating distinct histological morphologies, these subtypes have variable underlying genetic alterations. Conventional chondrosarcomas present an upregulated Hedgehog pathway, which plays a role in cartilage tumorigenesis [30, 31]. Proto-oncogene tyrosine-protein kinase Src, phosphoinositide 3-kinase (PI3k)/serine-threonine protein kinase Akt/mammalian target of rapamycin (PI3k-Akt-mTOR) and angiogenesis are other activated pathways in conventional chondrosarcomas $[32,33]$. The retinoblastoma (RB) and the p53 pathways are commonly affected in clear cell chondrosarcoma, mesenchymal chondrosarcoma and dedifferentiated chondrosarcoma [34]. In these subtypes, chromosomal aberrations are frequent, including loss of the CDKN2A/p16 locus [34].

There is currently no targeted therapy approved for chondrosarcoma, although encouraging results were seen in the phase 2 study of dasatinib, a small molecule tyrosine kinase inhibitor, with an overall response rate (ORR) of $15 \%$ and a 6-month progression-free survival (PFS) rate of $47 \%$ in chondrosarcoma patients [35, 36]. Vismodegib (previously known as GDC-0449), targeting the hedgehog pathway, has failed to show clinical benefit in a phase 2 trial conducted by 
Italiano et al.; however, some activity was noted in patients with progressive grade 1 or 2 chondrosarcoma [37]. IPI-926, an antagonist of the Hedgehog pathway, showed growth inhibition of chondrosarcoma xenografts [38]; however, a phase 2 placebo-controlled double-blind randomised study of IPI-926 in chondrosarcoma patients failed to demonstrate a survival benefit. Only a small subset of patients had dimensional tumour reduction in this trial (NCT01310816) [39].

Pazopanib, a multi-targeted tyrosine kinase inhibitor with activity against vascular endothelial growth factor (VEGF) and platelet-derived growth factor receptor alpha (PDGFRA), showed some benefit in terms of prolonged stable disease for patients with progressive chondrosarcoma and demonstrated objective response in a phase 2 trial enrolling patients with extraskeletal chondrosarcoma (NCT01330966, NCT02066285) [40, 41]. Regorafenib, another multi-kinase inhibitor molecule, has been studied in the setting of chondrosarcoma in the non-comparative phase 2 randomised, placebo-controlled clinical trial REGOBONE. The results have been presented at ESMO 2019 and revealed an improved median progression-free survival of 19.4 weeks in the regorafenib arm compared to 8 weeks in the placebo arm, and this difference was maintained at 24 weeks [42].

Other targets such as anti-death receptor 5 (anti-DR5) failed to show a benefit, and the phase 2 trial of anti-DR5 was terminated early due to lack of efficacy in patients with chondrosarcoma (NCT00543712).

Current research is focusing on other molecular targets, with ongoing clinical trials assessing inhibitors of the PI3kAkt-mTOR pathway (NCT02008019) and histone deacetylase (HDAC) inhibitors in the management of chondrosarcoma (NCT00112463) [43]. Survivin, the antiapoptotic protein, is an attractive target in chondrosarcoma due to its high expression in high-grade chondrosarcomas, and targeting survivin in chondrosarcoma cell lines has shown promise [44, 45].

Glutaminolysis and NAD synthesis pathways are potentially other vulnerable targets in the context of $I D H$ mutated chondrosarcomas, but their clinical applications remain to be determined $[46,47]$.

\section{IDH Mutations in Chondrosarcoma-Histopathological and Clinical Characteristics}

The first documentation of $I D H$ mutations in a mesenchymal tumour was reported in 2011 by Amary et al. The team analysed 145 samples of cartilaginous tumours and found that $56 \%$ had a mutation in either IDH1 or IDH2 [48]. No mutations were found in peripheral chondrosarcoma or in the osteochondroma tissues tested, and both low-grade and high-grade chondrosarcomas exhibited the mutation. One striking difference was the anatomic location, with $90 \%$ of tumours of the hand and feet harbouring $I H D 1 / 2$ mutations, compared to only $53.2 \%$ of tumours located in the long bones and $53.1 \%$ in the flat bones [48]. Of note, this study determined IDH1 mutational status through immunohistochemistry rather than DNA sequencing which may impact on the reliability of these results.

IDH mutations have also been demonstrated in head and neck chondrosarcomas. In a series of 88 cases, $I D H$ mutation was present in $64.5 \%$ of craniofacial chondrosarcoma, but was infrequent in laryngeal and tracheal cartilage chondrosarcoma, being mutated in only $11.8 \%$ of these cases [49].

Clear cell chondrosarcoma and mesenchymal chondrosarcoma do not harbour IDH1 or IDH2 mutations, as opposed to dedifferentiated chondrosarcoma which harbours a mutation in one of these genes in $50-76 \%$ of cases [34, 50, 51].

Due to the high incidence of IDH1 and IDH2 mutations in dedifferentiated and conventional chondrosarcomas, the presence of an $I D H$ mutation could be useful in distinguishing chondrosarcoma from other bone tumours, such as undifferentiated pleomorphic sarcoma (UPS) of the bone. In a study that looked at UPS arising in bone, none of the samples harboured an $I D H 1$ or $I D H 2$ mutation and this characteristic could have important implications due to the different clinical behaviour of UPS and chondrosarcoma [52]. The management of the UPS of the bone comprises neoadjuvant or adjuvant chemotherapy, offering an improved 5-year survival rate up to $59 \%$, as opposed to the poor response to chemotherapy in chondrosarcomas [53]. Amary et al. have also documented that an IDH mutation present in the primary tumour is maintained in local recurrences and metastases from that specific tumour, suggesting that it may be an early driver event in the disease [54].

Maffucci syndrome is a rare congenital non-hereditary disorder presenting as a combination of enchondromatosis (also known as Ollier disease) and haemangiomatosis. Both Maffucci syndrome and Ollier disease interfere with the normal development of tissues leading to physical deformities, and predisposing those affected to secondary neoplasms, such as chondrosarcomas, gliomas, and pancreatic and ovarian cancers, observed in up to $25 \%$ of patients with Ollier disease and Maffucci syndrome [55-58]. Apart from secondary neoplasms, malignant transformation of enchondromas to chondrosarcomas occurs in $>30 \%$ of these patients [59-61].

In another study by Amary and colleagues, about $90 \%$ of tumours of patients with Ollier disease and Maffucci syndrome harboured an IDH1 or IDH2 mutation [62]. Similar findings were published by Pansuriya et al., where $81 \%$ of patients with Ollier disease and $77 \%$ of patients affected by Maffucci syndrome carried a somatic mutation of IDHI $(98 \%)$ or IDH2 (2\%) [63]. Furthermore, mutation of the IDH1 gene was associated with hypermethylation and downregulation of multiple different genes, with their role in the 
formation of enchondromas and haemangiomatosis yet to be confirmed [63, 64]. Based on the prevalence of $I D H$ mutations in Ollier disease and Maffucci syndrome, it has been suggested that mutated $I D H$ is an early driver event in these conditions and could be the precursor mutation that predisposes the malignant transformation of enchondromas to chondrosarcoma; however, more research is needed to determine the role of $I D H$ mutations in the malignant transformation of enchondromas.

Long-term outcomes did not differ in a series of patients with chondrosarcomas harbouring $I D H$ mutations when compared to $I D H$ wild-type chondrosarcoma [65]. In contrast, IDH1 and IDH2 mutant chondrosarcoma had worse outcomes relative to $I D H$ wild-type chondrosarcoma in another study reported by Lugowksa et al. [66]. The authors of both studies performed correlation with the tumour grade; however, the histological subtype was not investigated. The differences between the two reports could be explained by the lack of histological subtype analysis, as some chondrosarcoma subtypes have a more aggressive clinical course than others. In another recent study, IDHI and $I D H 2$ mutations were associated with longer relapse-free (measured as the time from surgery to relapse or metastatic disease) and metastasis-free survival (measured as the time from initial diagnosis to the appearance of metastases) in high-grade chondrosarcomas, excluding de-differentiated chondrosarcoma. However, no significant impact of $I D H$ status on overall survival was noted in this study [67].

\section{Targeting the IDH Pathway—Preclinical Data}

As previously discussed, mutations of the $I D H 1$ and $I D H 2$ genes result in DNA methylation via the accumulation of D-2-hydroxyglutarate. The most affected hypermethylated genes in $I D H$ mutant samples are retinoic acid receptor alpha, platelet-derived growth factor subunit A (PDGFA) and B cell lymphoma 6 protein corepressor gene $(B C O R)$, suggesting that $I D H$ mutations are associated with epigenetic dysregulation of genes implicated in stem cell maintenance, regulation and dedifferentiation [68]. Expression of the IDH2 mutant protein in a mesenchymal multipotent cell line resulted in high levels of 2HG, hindered differentiation into adipocytic and chondrocytic cells and resulted in tumour formation in vivo [68].

Preclinical work in the TS603 glioma cell line, characterised by a heterozygous $R 132 \mathrm{H}-\mathrm{IDH} 1$ mutation, showed that a selective R132H-IDH1 inhibitor (AGI-5198) blocked the formation of 2-HG. This process induced demethylation of histone $\mathrm{H} 3 \mathrm{~K} 9 \mathrm{me} 3$, delayed tumoural growth and promoted differentiation of glioma cells [69]. Interestingly, genome-wide DNA methylation was not affected in this experiment, raising the possibility that $I D H 1$ mutation might promote tumorigenesis through other transcriptional mechanisms, independent of DNA methylation.
Similar positive results were noted in AML cell lines. The small molecule inhibitor AGI-6780 was active against R140Q-IDH2 mutant human AML cells in an experiment conducted by Wang and colleagues [70]. The inhibition of R140Q-IDH2 mutant cell by AGI- 6780 promoted differentiation of TF-1 erythroleukaemia and human AML cells in vitro and reversed IDH2 mutation-induced histone and DNA hypermethylation $[15,70]$.

$\mathrm{Li}$ and colleagues used AGI-5981 to treat JJ012 (chondrosarcoma cell line) and HT1080 (fibrosarcoma cell line), two human $I D H$-mutated cell lines and the chondrocyte cell line C28, which is $I D H$ wild type. AGI-5198 decreased the 2-HG levels and inhibited tumour colony formation and migration, inducing apoptosis in the $I D H$-mutated chondrosarcoma and fibrosarcoma cells [71]. Another experiment using the $I D H$ mutated chondrosarcoma cell lines JJ012, L835, SW1353 and L2975, treated with AGI-5981, resulted in decreased levels of 2-HG, but the tumorigenic properties were not affected, in contrast with previous preclinical work [72].

\section{Clinical Data with IDH Inhibitors}

\section{Ivosidenib and Enasidenib: First-in-Class IDH1 and IDH2 Inhibitors}

$I D H 1$ and $I D H 2$ mutated proteins have become an attractive target in the treatment of cancers harbouring these mutations [73]. Ivosidenib (previously known as AG-120), is a first-inclass selective oral IDH1 inhibitor that targets the mutant IDH1 protein and was developed by Agios Pharmaceuticals. It showed clinical activity in a phase 1 , open-label, multicentre study with 168 patients with advanced solid tumours (NCT02073994) [74, 75]. Enasidenib, also known as AG221, another IDH inhibitor developed by Agios Pharmaceuticals, is a first-in-class orally potent selective IDH2 inhibitor, targeting the mutant IDH2 enzymes [76]. Ongoing trials with enasidenib are recruiting patients with IDH2 mutations (NCT03515512, NCT03728335).

\section{Toxicity Profile of IDH Inhibitors}

The phase 1 data of ivosidenib showed rapid oral absorption and a long half-life of 40 to $102 \mathrm{~h}$ after one single administration of the drug [75]. Ivosidenib had an acceptable tolerability profile, with only few dose reductions or discontinuations due to toxicities noted in the phase 1 trial; the most frequent side effects encountered in the AML population were diarrhoea, leucocytosis, febrile neutropenia, nausea, fatigue, QT prolongation, pyrexia and anaemia [77]. In the cholangiocarcinoma cohort of the same trial, the most frequent side effects of ivosidenib reported were fatigue, nausea, diarrhoea, 
Table 1 Clinical trials with IDH1 and IDH2 inhibitors enrolling patients with chondrosarcoma that harbour an IDH1 or IDH2 mutation

\begin{tabular}{lllll}
\hline Clinical trial & Drug & Sponsor & Conditions & Outcomes in chondrosarcoma \\
\hline NCT02073994 & AG-120 & Agios Pharmaceuticals & IDH1 mutated solid tumours & $\begin{array}{l}\text { SD: 55\% } \\
\text { PFS rate at 3 months: 58\% } \\
\text { SD }>6 \text { months: 36\% (CTOS 2016, } \\
\text { poster 138) [80] }\end{array}$ \\
& & & & Results published in AML [82] \\
NCT02273739 & AG-221 & Agios Pharmaceuticals & IDH2 mutated solid tumours & Recruiting \\
NCT03684811 & FT-2102 & Forma Therapeutics & IDH1 mutated solid tumours & Suspended due to liver toxicity \\
NCT02381886 & IDH305 & Novartis Pharmaceuticals & IDH1R132 mutated solid tumours & population (NCT02826642) \\
NCT02746081 & BAY1436032 & Bayer & IDH1 mutant solid tumours & $\begin{array}{c}\text { Not recruiting } \\
\text { Preliminary results presented in } \\
\text { glioma patients [85] }\end{array}$ \\
NCT02481154 & AG-881 & Agios Pharmaceuticals & IDH1 or 2 mutated solid tumours & Not yet recruiting
\end{tabular}

abdominal pain, decreased appetite and vomiting [78, 79]. The chondrosarcoma patients experienced decreased appetite, long QT, nausea, anaemia and peripheral oedema [80]. In the glioma cohort of the same trial, the most frequent adverse events reported were diarrhoea, headaches, nausea, neutrophil decrease and vomiting [81].

Enasidenib has a slightly different toxicity profile. In the phase 1 trial with enasidenib in AML, the most common adverse events were indirect hyperbilirubinaemia and nausea. Grade 3 and 4 adverse events occurred in 99 patients out of a total of 239 evaluable patients $(41 \%)$, the most common being indirect hyperbilirubinaemia in 29 patients (12\%) and IDH-inhibitor-associated differentiation syndrome (IDH-DS) in 15 patients $(6 \%)$. Other common toxicities were haematological toxicities and infections, leucocytosis and tumour-lysis syndrome [82].

\section{The Activity of IDH Inhibitors in Clinical Trials}

In $\mathrm{IDH} 1$ mutated AML, ivosidenib showed very encouraging results. The rate of complete remission or complete remission with partial haematologic recovery was $30.4 \%$, and the overall response rate was $41.6 \%$ in patients with $I H D 1$ mutated AML [77]. In July 2018, the FDA granted approval for ivosidenib for treatment of patients with $I D H 1$ mutant relapsed or refractory AML [83].

IDH1 mutant cholangiocarcinoma patients had a 6-month progression-free survival rate of $40.1 \%$ and median progression-free survival of 3.8 months in the phase 1 trial of ivosidenib [79]. Median overall survival was 13.8 months; however, the results are not mature, as only $66 \%$ of patients were censored at the time of publication [79]. The results of the phase 3 study of ivosidenib versus placebo in IDH1 mutated cholangiocarcinoma have been recently presented at the ESMO 2019 congress (NCT02989857) [84]. This randomised placebo-controlled trial enrolled 185 patients with advanced cholangiocarcinoma and IDH1 mutation. The median PFS was improved in the ivosidenib arm, 2.7 months compared to 1.4 months in the placebo arm. More interestingly, the 6and 12-month PFS rates were $32.0 \%$ and $21.9 \%$ with ivosidenib, compared to none of the patients on placebo being progression free at 6 months or more [84].

In the chondrosarcoma cohort of the initial phase 1 trial of ivosidenib (NCT02073994), out of twenty evaluable patients, $55 \%$ (11 patients) achieved stable disease as their best response. The progression-free survival rate at 3 months was $58 \%$. Four patients had stable disease for more than 6 months. One patient experienced tumour shrinkage, achieving stable disease as best response and remaining on study for 49 weeks [80]. Current ongoing trials with IDH inhibitors enrolling chondrosarcoma patients are listed in Table 1.

In the phase 1 trial of enasidenib, complete remission was noted in $19.3 \%$ of patients with $I D H 2$ mutated relapsed/ refractory AML. The overall response rate for AML was $40.3 \%$, and $10 \%$ of patients discontinued enasidenib to proceed with stem cell transplant [82]. Enasidenib has received regular approval from the FDA in August 2017 for the treatment of relapsed or refractory acute myeloid leukaemia with an $\mathrm{IDH} 2$ mutation detected [86].

The IDH1 inhibitor, FT-2102, is currently being evaluated in a phase 2 trial, with a Simon 2-stage design (NCT03684811). In the first stage, 8 patients with advanced chondrosarcoma will be treated with single-agent FT-2102. If one or more patients have a partial response, then a further 15 patients will be treated with single-agent FT-2102 in the second stage. If no partial responses are documented in the first stage, then chondrosarcoma patients will be treated with combination FT-2102 and 5-azacitidine.

AG-881, a selective oral potent inhibitor of IDH1 and IDH2 mutated proteins, has shown positive results in glioma patients, with one sustained partial response and one minor response confirmed out of 52 patients with glioma enrolled, and another $69 \%$ of patients $(n=36)$ had stable disease as best response [85]. The 
most common side effects encountered were mild to moderate and included raised ALT and AST, headaches and fatigue. However, grade 3 or higher side effects were seen in 19\% of patients, with one patient experiencing seizures and ALT and AST elevation [85]. Another drug, IDH305, a selective IDH1R132 inhibitor, was halted in development, due to liver toxicity encountered in AML patients (NCT02826642).

\section{Conclusions}

In conclusion, to date, there are two IDH inhibitors which have received FDA approval for the treatment of AML harbouring $I D H 1$ or $I D H 2$ mutations and their toxicity profile is tolerable. The results of the phase 3 trial of ivosidenib in IDH1 mutated cholangiocarcinoma have been presented recently and showed an improved PFS in patients with cholangiocarcinoma harbouring this mutation [84]. However, acquired resistance to IDH inhibitors has already been documented in two AML patients, where a second site $I D H 2$ resistance mutation was found after an initial response to enasidenib [87]. Acquired drug resistance is likely to be the next challenge that needs to be addressed in the treatment paradigm of $I D H$ mutant AML patients.

Treatment options for patients with advanced chondrosarcoma are limited, with no proven effective systemic therapy. The presence of IDH1 or IDH2 mutations in $50-80 \%$ of chondrosarcomas suggests that $I D H$ mutations may be a druggable target in this disease. This is supported by promising preclinical data. However, available published clinical data have to a certain extent been disappointing, with disease stabilisation being the best response by RECIST. Advanced chondrosarcoma can be relatively indolent, and the significance of disease stabilisation is therefore difficult to interpret in singlearm trials. Furthermore, there are a number of ongoing trials of IDH inhibitors which include chondrosarcoma. The results of these trials are eagerly awaited and may show that targeting the $I D H$ mutation is effective in chondrosarcomas.

However, if these trials report a lack of efficacy with monotherapy, then combination therapies could potentially be evaluated in carefully stratified trials. Ivosidenib in combination with nivolumab will be investigated in a phase 2 trial which will enrol patients with gliomas and solid tumours with an IDH1 mutation (NCT04056910). Chondrosarcomas express NY-ESO-1 or LAGE-1s in approximately $36 \%$ of cases, and this expression was increased in an experiment where chondrosarcoma cells were treated with 5-aza-2-deoxycitabin (5-Aza-dC) [88]. The potential use of combinations of immune checkpoint inhibitors with 5-aza-dc may prove effective in increasing the immunogenicity of chondrosarcomas. Preclinical results in gliomas with $I D H 1$ mutations revealed the presence of CD4+ antitumor $\mathrm{T}$ cell response, but such an immune response has not been validated yet in $I D H$ mutated chondrosarcoma [89, 90].

The combination of metformin, an oral antidiabetic medication, and chloroquine, an oral antimalarial drug, has shown activity against the 2-HG oncometabolite, and an ongoing clinical trial using these two agents is enrolling patients with IDH1 or IDH2 mutated solid tumours (NCT02496741) [91].

\section{IDH and 2-HG as Biomarkers in Chondrosarcoma}

$I D H$ status is an emerging biomarker in the context of chondrosarcomas. The presence of an $I D H$ mutation could lead to tailored treatment in chondrosarcomas, and the use of 2-HG could potentially correlate with the tumour burden in solid cancers. Further studies are required to ascertain whether this could be used as a predictive marker of response to therapy [92]. Finally, $I D H$ status is correlated with longer relapsefree and metastasis-free survival in high-grade chondrosarcomas, but the impact on overall survival requires further evaluation.

Funding This research did not receive any specific grant from funding agencies in the public, commercial or not-for-profit sectors. This work was undertaken in The Royal Marsden NHS Foundation Trust together with The Institute of Cancer Research which receives BRC funding through the National Institute for Health Research (NIHR).

\section{Compliance with Ethical Standards}

Conflict of Interest Elena Cojocaru declares nothing to disclose.

Christopher Wilding declares nothing to disclose.

Bodil Engelman declares nothing to disclose.

Paul Huang declares nothing to disclose.

Robin L. Jones is a consultant for Adaptimmune, Athenex, Blueprint, Clinigen, Eisai, Epizyme, Daichii, Deciphera, Helsinn, Immunedesign, Lilly, Merck, Pharmamar, Tracon, and UpToDate and a current investigator on the phase 2 trial of IDH1 inhibitor sponsored by Forma Therapeutics.

Open Access This article is licensed under a Creative Commons Attribution 4.0 International License, which permits use, sharing, adaptation, distribution and reproduction in any medium or format, as long as you give appropriate credit to the original author(s) and the source, provide a link to the Creative Commons licence, and indicate if changes were made. The images or other third party material in this article are included in the article's Creative Commons licence, unless indicated otherwise in a credit line to the material. If material is not included in the article's Creative Commons licence and your intended use is not permitted by statutory regulation or exceeds the permitted use, you will need to obtain permission directly from the copyright holder. To view a copy of this licence, visit http://creativecommons.org/licenses/by/4.0/. 


\section{References}

1. Yasutake Y, Watanabe S, Yao M, Takada Y, Fukunaga N, Tanaka I. Structure of the monomeric isocitrate dehydrogenase: evidence of a protein monomerization by a domain duplication. Structure. 2002;10(12):1637-48.

2. Yasutake Y, Watanabe S, Yao M, Takada Y, Fukunaga N, Tanaka I. Crystal structure of the monomeric isocitrate dehydrogenase in the presence of NADP+: insight into the cofactor recognition, catalysis, and evolution. J Biol Chem. 2003;278(38):36897-904.

3. Chowdhury R, Yeoh KK, Tian Y-M, Hillringhaus L, Bagg EA, Rose NR, et al. The oncometabolite 2-hydroxyglutarate inhibits histone lysine demethylases. EMBO Rep. 2011;12(5):463-9.

4. Clark O, Yen K, Mellinghoff IK. Molecular pathways: isocitrate dehydrogenase mutations in cancer. Clin Cancer Res. 2016;22(8): 1837-42.

5. Medeiros BC, Fathi AT, DiNardo CD, Pollyea DA, Chan SM, Swords R. Isocitrate dehydrogenase mutations in myeloid malignancies. Leukemia. 2017;31(2):272-81.

6. Waitkus MS, Diplas BH, Yan H. Biological role and therapeutic potential of IDH mutations in cancer. Cancer Cell [internet]. 2018;34(2):186-195 https://doi.org/10.1016/j.ccell.2018.04.011.

7. Yang H, Ye D, Guan K, Xiong Y. IDH1 and IDH2 mutations in tumorigenesis: mechanistic insights and clinical perspectives. Clin Cancer Res. 2012;18(20):5562-72.

8. Tommasini-Ghelfi S, Murnan K, Kouri FM, Mahajan AS, May JL, Stegh AH. Cancer-associated mutation and beyond: the emerging biology of isocitrate dehydrogenases in human disease. Sci Adv. 2019:1-18.

9. Dang L, White DW, Gross S, Bennett BD, Bittinger MA, Driggers EM, et al. Cancer-associated IDH1 mutations produce 2hydroxyglutarate. Nature. 2010;465(7300):966.

10. Dang L, Yen K, Attar EC. IDH mutations in cancer and progress toward development of targeted therapeutics. Ann Oncol. 2016;27: 599-608.

11. Parsons DW, Jones S, Zhang X, Lin JC-H, Leary RJ, Angenendt P, et al. An integrated genomic analysis of human glioblastoma multiforme. Science. 2008;321(5897):1807-12.

12. Dang L, Jin S, Su SM. IDH mutations in glioma and acute myeloid leukemia. Trends Mol Med [Internet] 2010;16(9):387-397. Available from: https://doi.org/10.1016/j.molmed.2010.07.002

13. Weller M, Felsberg J, Hartmann C, Berger H, Steinbach JP, Schramm J, et al. Molecular predictors of progression-free and overall survival in patients with newly diagnosed glioblastoma: a prospective translational study of the German Glioma Network. J Clin Oncol. 2009;27(34):5743-50.

14. Montalban-Bravo G, DiNardo CD. The role of IDH mutations in acute myeloid leukemia. Future Oncol. 2018;14(10):979-93.

15. Kernytsky A, Wang F, Hansen E, Schalm S, Straley K, Gliser C, et al. IDH2 mutation-induced histone and DNA hypermethylation is progressively reversed by small-molecule inhibition. Blood. 2015;125(2):296-303.

16. Galm O, Wilop S, Luders C, Jost E, Gehbauer G, Herman JG, et al. Clinical implications of aberrant DNA methylation patterns in acute myelogenous leukemia. Ann Hematol. 2005;84(Suppl 1):39-46.

17. Marcucci G, Maharry K, Wu Y-Z, Radmacher MD, Mrozek K, Margeson D, et al. IDH1 and IDH2 gene mutations identify novel molecular subsets within de novo cytogenetically normal acute myeloid leukemia: a Cancer and Leukemia Group B study. J Clin Oncol. 2010;28(14):2348-55.

18. Ho PA, Alonzo TA, Kopecky KJ, Miller KL, Kuhn J, Zeng R, et al. Molecular alterations of the IDH1 gene in AML: a Children's Oncology Group and Southwest Oncology Group study. Leukemia. 2010;24(5):909-13.
19. Borger DR, Tanabe KK, Fan KC, Lopez HU, Fantin VR, Straley $\mathrm{KS}$, et al. Frequent mutation of isocitrate dehydrogenase (IDH) 1 and IDH2 in cholangiocarcinoma identified through broad-based tumor genotyping. Oncologist. 2012;17(1):72-9.

20. Wang P, Dong Q, Zhang C, Kuan P-F, Liu Y, Jeck WR, et al. Mutations in isocitrate dehydrogenase 1 and 2 occur frequently in intrahepatic cholangiocarcinomas and share hypermethylation targets with glioblastomas. Oncogene. 2013;32(25):3091-100.

21. Saha SK, Parachoniak CA, Ghanta KS, Fitamant J, Ross KN, Najem MS, Gurumurthy S, Akbay EA, Sia D, Cornella H, Miltiadous O, Walesky C, Deshpande V, Zhu AX, Hezel AF, Yen KE, Straley KS, Travins J, Popovici-Muller J, Gliser C, Ferrone CR, Apte U, Llovet JM, Wong KK, Ramaswamy S, Bardeesy N Mutant IDH inhibits HNF- $4 \alpha$ to block hepatocyte differentiation and promote biliary cancer. Nature [Internet] 2014;513(7516):110 152. Available from: https://doi.org/10.1038/nature13441

22. Amary MF, Bacsi K, Maggiani F, Damato S, Halai D, Berisha F, et al. IDH1 and IDH2 mutations are frequent events in central chondrosarcoma and central and periosteal chondromas but not in other mesenchymal tumours. J Pathol. 2011;224(3):334-43.

23. Cote GM, He J, Choy E. Next-generation sequencing for patients with sarcoma: a single center experience. Oncologist. 2018;23(2): 234-42.

24. Bjornsson J, McLeod RA, Unni KK, Ilstrup DM, Pritchard DJ. Primary chondrosarcoma of long bones and limb girdles. Cancer. 1998;83(10):2105-19.

25. Gelderblom H, Hogendoorn PCW, Dijkstra S, Van Rijswijk C, Krol A, Taminiau A, et al. The clinical approach towards chondrosarcoma. Oncologist 2008;13(0):320-329.

26. van Maldegem A, Conley AP, Rutkowski P, Patel SR, Lugowska I, Desar IME, et al. Outcome of first-line systemic treatment for unresectable conventional, dedifferentiated, mesenchymal, and clear cell chondrosarcoma. Oncologist. 2019;24(1):110-6.

27. Milchgrub S, Hogendoorn PCW. Dedifferentiated chondrosarcoma. In: World Health Organization classification of tumours of soft tissue and bone. 2002. p. 252-4.

28. Liu C, Xi Y, Li M, Jiao Q, Zhang H, Yang Q, et al. Dedifferentiated chondrosarcoma: radiological features, prognostic factors and survival statistics in 23 patients. PLoS One. 2017;12(3):1-15.

29. Antonescu CR, Argani P, Erlandson RA, Healey JH, Ladanyi M, Huvos AG. Skeletal and extraskeletal myxoid chondrosarcoma: a comparative clinicopathologic, ultrastructural, and molecular study. Cancer. 1998;83(8):1504-21.

30. Ng JMY, Curran T. The Hedgehog's tale: developing strategies for targeting cancer. Nat Rev Cancer. 2011;11(7):493-501.

31. Tiet TD, Hopyan S, Nadesan P, Gokgoz N, Poon R, Lin AC, et al. Constitutive hedgehog signaling in chondrosarcoma up-regulates tumor cell proliferation. Am J Pathol. 2006;168(1):321-30.

32. Polychronidou G, Karavasilis V, Pollack SM, Huang PH, Lee A, Jones RL. Novel therapeutic approaches in chondrosarcoma. Future Oncol. 2017;13:637-48.

33. Speetjens FM, de Jong Y, Gelderblom H, Bovee JVMG. Molecular oncogenesis of chondrosarcoma: impact for targeted treatment. Curr Opin Oncol. 2016;28(4):314-22.

34. Meijer D, de Jong D, Pansuriya TC, van den Akker BE, Picci P, Szuhai K, et al. Genetic characterization of mesenchymal, clear cell, and dedifferentiated chondrosarcoma. Genes Chromosomes Cancer. 2012;51(10):899-909.

35. Schuetze SM, Bolejack V, Choy E, Ganjoo KN, Staddon AP, Chow WA, et al. Phase 2 study of dasatinib in patients with alveolar soft part sarcoma, chondrosarcoma, chordoma, epithelioid sarcoma, or solitary fibrous tumor. Cancer. 2017;123(1):90-7.

36. Villalobos VM, Hoffner B, Elias AD. We can study ultrarare tumors effectively in this day and age, it just takes a cooperative approach: the role of dasatinib in assorted indolent sarcomas. In: Cancer, vol. 123. United States; 2017. p. 20-4. 
37. Italiano A, Le Cesne A, Bellera C, Piperno-Neumann S, Duffaud F, Penel N, et al. GDC-0449 in patients with advanced chondrosarcomas: a French Sarcoma Group/US and French National Cancer Institute Single-Arm Phase II Collaborative Study. Ann Oncol Off J Eur Soc Med Oncol. 2013;24(11):2922-6.

38. Campbell VT, Nadesan PP, Wang Y, Whetstone H, McGovern K, Read M. Abstract LB-380: direct targeting of the hedgehog pathway in primary chondrosarcoma xenografts with the smoothened inhibitor IPI-926. In: AACR 102nd Annual Meeting. 2011.

39. Wagner A, Hohenberger P, Okuno S, Eriksson M, Patel S, Ferrari S, et al. Results from a phase 2 randomized, placebo-controlled, double blind study of the hedgehog pathway antagonist IPI-926 in patients with advanced chondrosarcoma. CTOS: In; 2013.

40. Jones RL, Katz D, Loggers ET, Davidson D, Rodler ET, Pollack SM. Clinical benefit of antiangiogenic therapy in advanced and metastatic chondrosarcoma. Med Oncol. 2017;34(10):167.

41. Stacchiotti S, Ferrari S, Redondo A, Hindi N, Palmerini E, Vaz Salgado MA, et al. Pazopanib for treatment of advanced extraskeletal myxoid chondrosarcoma: a multicentre, single-arm, phase 2 trial. Lancet Oncol. 2019;20(9):1252-62.

42. Duffaud F, Blay JY, Italiano A, Al E. Results of the randomized, placebo-controlled phase 2 study evaluating the efficacy and safety of regorafenib in patients with locally advanced or metastatic relapsed chondrosarcoma. ESMO: In; 2019.

43. van Maldegem AM, Bovee JV, Gelderblom H. Comprehensive analysis of published studies involving systemic treatment for chondrosarcoma of bone between 2000 and 2013. Clin Sarcoma Res. 2014;4:11.

44. Jong Y De, Oosterwijk JG Van, Kruisselbrink AB, Bruijn IHB, Agrogiannis G, Baranski Z, et al. Targeting survivin as a potential new treatment for chondrosarcoma of bone. Oncogenesis. 2016;5, e222(March).

45. Lechler P, Renkawitz T, Campean V, Balakrishnan S, Tingart M, Grifka J, et al. The antiapoptotic gene survivin is highly expressed in human chondrosarcoma and promotes drug resistance in chondrosarcoma cells in vitro. BMC Cancer. 2011;11:120.

46. Peterse EFP, Niessen B, Addie RD, de Jong Y, Cleven AHG, Kruisselbrink $A B$, et al. Targeting glutaminolysis in chondrosarcoma in context of the IDH1/2 mutation. Br J Cancer. 2018;118(8):1074-83.

47. Peterse EFP, van den Akker BEWM, Niessen B, Oosting J, Suijker $\mathrm{J}$, de Jong $\mathrm{Y}$, et al. NAD synthesis pathway interference is a viable therapeutic strategy for chondrosarcoma. Mol Cancer Res. 2017;15(12):1714-21.

48. Amary MF, Bacsi K, Maggiani F, Damato S, Halai D, Berisha F, et al. IDH1 and IDH2 mutations are frequent events in central chondrosarcoma and central and periosteal chondromas but not in other mesenchymal tumours. 2011;(May):334-343.

49. Tallegas M, Miquelestorena-standley É. IDH mutation status in a series of 88 head and neck chondrosarcomas : different pro fi le between tumors of the skull base and tumors involving the facial skeleton and the laryngotracheal tract. is. Hum Pathol [internet]. 2019;84:183-91 Available from: https://doi.org/10.1016/j. humpath.2018.09.015.

50. Mohammad N, Wong D, Lum A, Lin J, Ho J, Lee C-H, et al. Characterization of IDH1/IDH2 mutation and D-2hydroxyglutarate oncometabolite level in dedifferentiated chondrosarcoma. Histopathology 2019 Oct;

51. de Andrea CE, San-Julian M, Bovee JVMG. Integrating morphology and genetics in the diagnosis of cartilage tumors. Surg Pathol Clin. 2017;10(3):537-52.

52. Chen S, Fritchie K, Wei S, Ali N, Curless K, Shen T, et al. Diagnostic utility of IDH $1 / 2$ mutations to distinguish dedifferentiated chondrosarcoma from undifferentiated pleomorphic sarcoma of bone. Hum Pathol. 2017;65:239-46.
53. Bramwell VH, Steward WP, Nooij M, Whelan J, Craft AW, Grimer RJ, et al. Neoadjuvant chemotherapy with doxorubicin and cisplatin in malignant fibrous histiocytoma of bone: a European Osteosarcoma Intergroup study. J Clin Oncol. 1999;17(10):3260-9.

54. Amary MF, Ye H, Forbes G, Damato S, Maggiani F, Pollock R, et al. Isocitrate dehydrogenase 1 mutations ( IDH1 ) and p16/ CDKN2A copy number change in conventional chondrosarcomas. 2015;217-22.

55. McGarry ME. Long term oncologic surveillance in Maffucci syndrome: a case report. J Oncol Sci [internet]. 2017;3(3):140-144 Available from: https://doi.org/10.1016/j.jons.2017.08.003.

56. Christman JE, Ballon SC. Ovarian fibrosarcoma associated with Maffucci's syndrome. Gynecol Oncol. 1990;37(2):290-1.

57. Lissa FCT, Argente JS, Antunes GN, Basso Fde O, Furtado J. Maffucci syndrome and soft tissue sarcoma: a case report. Int Semin Surg Oncol. 2009;6:2.

58. Hao S, Hong CS, Feng J, Yang C, Chittiboina P, Zhang J, et al. Somatic IDH1 mutation in a pituitary adenoma of a patient with Maffucci syndrome. J Neurosurg. 2016;124(6):1562-7.

59. Herget GW, Strohm P, Rottenburger C, Kontny U, Krauss T, Bohm $\mathrm{J}$, et al. Insights into enchondroma, enchondromatosis and the risk of secondary chondrosarcoma. Review of the literature with an emphasis on the clinical behaviour, radiology, malignant transformation and the follow up. Neoplasma. 2014;61(4):365-78.

60. Sassoon AA, Fitz-Gibbon PD, Harmsen WS, Moran SL. Enchondromas of the hand: factors affecting recurrence, healing, motion, and malignant transformation. J Hand Surg Am. 2012;37(6):1229-34.

61. Guo J, Gao J-Z, Guo L-J, Yin Z-X, He E-X. Large enchondroma of the thoracic spine: a rare case report and review of the literature. BMC Musculoskelet Disord. 2017;18(1):155.

62. Amary MF, Damato S, Halai D, Eskandarpour M, Berisha F, Bonar F, et al. Ollier disease and Maffucci syndrome are caused by somatic mosaic mutations of IDH1 and IDH2. Nat Genet. 2011;43(12): $1262-5$.

63. Pansuriya TC, van Eijk R, d'Adamo P, van Ruler MAJH, Kuijjer ML, Oosting J, et al. Somatic mosaic IDH1 and IDH2 mutations are associated with enchondroma and spindle cell hemangioma in Ollier disease and Maffucci syndrome. Nat Genet. 2011;43(12): 1256-61.

64. Hirata M, Sasaki M, Cairns RA, Inoue S, Puviindran V, Li WY, et al. Mutant IDH is sufficient to initiate enchondromatosis in mice. Proc Natl Acad Sci U S A. 2015;112(9):2829-34.

65. Cleven AHG, Suijker J, Agrogiannis G, De Bruijn IHB, Frizzell N, Hoekstra AS, et al. IDH1 or - 2 mutations do not predict outcome and do not cause loss of 5 - hydroxymethylcytosine or altered histone modifications in central chondrosarcomas. Clin Sarcoma Res. 2017:1-10.

66. Lugowska I, Teterycz P, Mikula M, Kulecka M, Kluska A, Balabas A. IDH1/2 mutations predict shorter survival in chondrosarcoma. J Cancer. 2018;9(6):998-1005.

67. Zhu G, Nafa K, Agaram N, Zehir A, Benayed R, Sadowska J, et al. Genomic profiling identifies association of IDH1/IDH2 mutation with longer relapse free and metastasis free survival in high-grade chondrosarcoma. Clin Cancer Res 2019 Oct;

68. Lu C, Venneti S, Akalin A, Fang F, Ward PS, Dematteo RG, et al. Induction of sarcomas by mutant IDH2. Genes Dev. 2013;27(18): 1986-98.

69. Rohle D, Popovici-Muller J, Palaskas N, Turcan S, Grommes C, Campos C, et al. An inhibitor of mutant IDH1 delays growth and promotes differentiation of glioma cells. Science. 2013;340(6132): 626-30.

70. Wang F, Travins J, Delabarre B, Penard-lacronique V, Schalm S, Hansen E, et al. Targeted inhibition of mutant IDH1 in leukemia cells induces cellular differentiation. Science (80- ). 2013;340:6227. 
71. Li L, Paz AC, Wilky BA, Johnson B, Galoian K. Treatment with a small molecule mutant IDH1 inhibitor suppresses tumorigenic activity and decreases production of the oncometabolite 2hydroxyglutarate in human chondrosarcoma cells. 2015;1-19.

72. Suijker J, Oosting J, Koornneef A, Struys EA, Gajja S, Schaap FG, et al. Inhibition of mutant IDH1 decreases D-2-HG levels without affecting tumorigenic properties of chondrosarcoma cell lines. Oncotarget. 6(14):12505-19.

73. Keum Y-S, Choi BY. Isocitrate dehydrogenase mutations: new opportunities for translational research. BMB Rep. 2015;48(5):26670.

74. Popovici-muller J, Lemieux RM, Artin E, Saunders O, Salituro FG, Travins J, et al. Discovery of AG-120 (ivosidenib): a first-in-class mutant IDH1 inhibitor for the treatment of IDH1 mutant cancers. ACS Med Chem. 2018;120(9):300-5.

75. Fan B, Mellinghoff IK, Wen PY, Lowery MA, Goyal L, Tap WD, et al. Clinical pharmacokinetics and pharmacodynamics of ivosidenib, an oral, targeted inhibitor of mutant IDH1, in patients with advanced solid tumors. Investig New Drugs. 2019.

76. Yen K, Travins J, Wang F, David MD, Artin E, Straley K, et al. AG221, a first-in-class therapy targeting acute myeloid leukemia harboring oncogenic IDH2 mutations. Cancer Discov. 2017;7(5):47893.

77. DiNardo CD, Stein EM, De Botton S, Roboz GJ, Altman J, ASM A, et al. Durable remissions with ivosidenib in IDH-1 mutated relapsed of refractory AML. N Engl J Med. 2018;378:2386-98.

78. Lowery M, Abou-Alfa G, Burris H, et al. Phase I study of AG-120, an IDH1 mutant enzyme inhibitor: results from the cholangiocarcinoma dose escalation and expansion cohorts. J Clin Oncol 2017;35(15 Suppl). 2017;35:abstrat 4015.

79. Lowery MA, Burris HA 3rd, Janku F, Shroff RT, Cleary JM, Azad NS, et al. Safety and activity of ivosidenib in patients with IDH1mutant advanced cholangiocarcinoma: a phase 1 study. Lancet Gastroenterol Hepatol. 2019;4(9):711-20.

80. Tap WD, Villalobos VM, Cote G, Burris $\mathrm{H}$ et al. A phase 1 study of AG-120, an IDH1 mutant enzyme inhibitor: results from the chondrosarcoma dose escalation and expansion cohorts. In: CTOS. 2016. p. Poster 138

81. Mellinghoff I, Touat M, Maher E, De La Fuente M, Cloughesy T, M $\mathrm{H}$, et al. AG-120, a first-in-class mutant IDH1 inhibitor in patients with recurrent or progressive IDH1 mutant glioma: updated results from the phase 1 non-enhancing glioma population. Neuro Oncol. 2017;19(suppl 6 .

82. Stein EM, DiNardo CD, Pollyea DA, Fathi AT, Roboz GJ, Altman $\mathrm{JK}$, et al. Enasidenib in mutant IDH2 relapsed or refractory acute myeloid leukemia. Blood. 2017;130(6):722-31.
83. Norsworthy KJ, Luo L, Hsu V, Gudi R, Dorff SE, Przepiorka D, et al. FDA approval summary: ivosidenib for relapsed or refractory acute myeloid leukemia with an isocitrate dehydrogenase- 1 mutation. Clin Cancer Res. 2019;25(11):3205-9.

84. Abou-Alfa G, Macarulla Mercade T, Javle M. Al. E. LBA10_PR ClarIDHy: a global, phase 3, randomized, double-blind study of ivosidenib (IVO) vs placebo in patients with advanced cholangiocarcinoma (CC) with an isocitrate dehydrogenase 1 (IDH1) mutation. ESMO: In; 2019.

85. Pharmaceuticals A. Agios Presents Updated Data from Phase 1 Dose-Escalation Study of AG-881 in Patients with IDH Mutant Positive Advanced Glioma [Internet]. [cited 2019 Sep 8]. Available from: http://investor.agios.com/news-releases/newsrelease-details/agios-presents-updated-data-phase-1-doseescalation-study-ag- 881

86. FDA.gov. https://www.fda.gov/drugs/resources-informationapproved-drugs/fda-granted-regular-approval-enasidenibtreatment-relapsed-or-refractory-aml [Internet]. [cited 2019 Sep 15]. Available from: https://www.fda.gov/drugs/resourcesinformation-approved-drugs/fda-granted-regular-approvalenasidenib-treatment-relapsed-or-refractory-aml

87. Intlekofer AM, Shih AH, Wang B, Nazir A, Rustenburg AS, Albanese SK, et al. Acquired resistance to IDH inhibition through trans or cis dimer-interface mutations. Nature. 2018;559(7712): 125-9.

88. Pollack SM, Li Y, Blaisdell MJ, Farrar EA, Chou J, Hoch BL, et al. NYESO-1/LAGE-1s and PRAME are targets for antigen specific $T$ cells in chondrosarcoma following treatment with 5-Aza-2deoxycitabine. PLoS One. 2012;7(2):e32165.

89. Schumacher T, Bunse L, Pusch S, Sahm F, Wiestler B, Quandt J, et al. A vaccine targeting mutant IDH1 induces antitumour immunity. Nature. 2014;512(7514):324-7.

90. Schumacher T, Bunse L, Wick W, Platten M. Mutant IDH1: an immunotherapeutic target in tumors. Oncoimmunology. 2014;3(12):e974392.

91. Molenaar RJ, Coelen RJS, Khurshed M, Roos E, Caan MWA, van Linde ME, et al. Study protocol of a phase IB/II clinical trial of metformin and chloroquine in patients with IDH1-mutated or IDH2-mutated solid tumours. BMJ Open. 2017;7(6):e014961.

92. Borger DR, Goyal L, Yau T, Poon RT, Ancukiewicz M, Deshpande $\mathrm{V}$, et al. Circulating oncometabolite 2-hydroxyglutarate is a potential surrogate biomarker in patients with isocitrate dehydrogenasemutant intrahepatic cholangiocarcinoma. 2014;20(7):1884-91.

Publisher's Note Springer Nature remains neutral with regard to jurisdictional claims in published maps and institutional affiliations. 